\title{
Coprocessamento de pneus inservíveis na indústria cimenteira
}

\author{
Mariana Vasconcelos Ferreira de Araújo \\ Instituto Federal Fluminense (IFFluminense) \\ (marifaraujo@gmail.com)
}

\begin{abstract}
Resumo: O pneu inservível é atrativo como combustível alternativo ao coque de petróleo e carvão mineral na indústria cimenteira devido ao seu elevado poder calorífico. A recuperação de energia contida nos resíduos contribui para a conservação de combustíveis fósseis não renováveis, reduzindo os custos de fabricação, pois os resíduos combustíveis são mais baratos do que qualquer combustível fóssil tradicional. A grande vantagem da utilização de pneus como resíduo combustível seria sua total destruição, em função das elevadas temperaturas de processo. As cinzas que seriam o resíduo resultante da queima são incorporadas ao cimento, em substituição a outras matérias-primas. Porém, o coprocessamento de pneus gera gases nocivos como monóxido de Carbono (CO), óxidos de enxofre $\left(\mathrm{SO}_{\mathrm{x}}\right)$, óxidos de nitrogênio $\left(\mathrm{NO}_{\mathrm{x}}\right)$, além de dioxinas e furanos. Neste trabalho, pretende-se identificar as normas para licenciamento da incineração ou coprocessamento de resíduos industriais, especificamente o pneu inservível, e os padrões para emissões de dioxinas e furanos no Brasil e no mundo. Além de identificar na literatura se o aumento da vida útil do pneu, que diminuiria a geração de pneus inservíveis, causa impactos em outras fases do seu ciclo de vida, inclusive na sua utilização como combustível.
\end{abstract}

Palavras-chave: Aproveitamento energético; Poluição atmosférica; Regulações.

\section{Co processing of inservible tires in the cement industry}

Abstract: The inservible tire is attractive as an alternative fuel replacing petcoke and mineral coal in the cement industry due to its high calorific value. The recovery of energy contained in wastes contributes to the conservation of non-renewable fossil fuels, reducing manufacturing costs, because fuel wastes are cheaper than any traditional fossil fuel. The great advantage of using tires as fuel waste would be their total destruction, due to the high process temperatures. The ashes that would be the residue resulting from the burning are incorporated into the cement, replacing other raw materials. However, the co processing of tires generates harmful gases such as carbon monoxide (CO), sulfur oxides (SO $x$ ), nitrogen oxides ( $\mathrm{NO} x$ ), as well as dioxins and furans. The objective of this work is to identify the regulations and standards for licensing the incineration or co processing of industry wastes, specifically the end-of-life tires, and the limit values for emissions of dioxins and furans in Brazil and worldwide. In addition, this work intends to identify in literature whether the improve of the tire useful life, which would reduce the generation of waste tires, may impact other phases of its life cycle, including its use as alternative fuel.

Keywords: energy recovery, air pollution, regulations.

\section{INTRODUÇÃO}

Até a década de 1960, pouca ou nenhuma preocupação era dirigida às questões ambientais, que eram consideradas secundárias em relação à maximização dos lucros 
financeiros imediatos, com raras exceções. A partir desta década, com a publicação do livro "Primavera Silenciosa" por Rachel Carson em 1962, considerado o primeiro alerta mundial contra o uso de pesticidas, motivou-se e inspirou-se a criação de agências de proteção e movimentos ambientalistas em vários países. Um pouco mais tarde, com a criação do Clube de Roma em 1968 e a divulgação do relatório "Limites do Crescimento" em 1972, cientistas, instituições e empresas se conscientizaram que esse regime de produção industrial e crescimento acima de tudo levava a Terra ao colapso (MEADOWS et al., 1972).

No final da década de 1980, a Comissão Mundial sobre o Meio Ambiente e Desenvolvimento (CMMAD) publicou o documento "Nosso Futuro Comum" ou, como é bastante conhecido, Relatório Brundtland, o qual apresentou um novo olhar sobre o desenvolvimento. O documento utilizou o termo "desenvolvimento sustentável" para descrever a forma como as atuais gerações satisfazem as suas necessidades sem, no entanto, comprometer a capacidade de as gerações futuras suprirem as suas próprias (WCED, 1987). No presente trabalho, será utilizado o termo "sustentabilidade", que é o mais aplicado por vários estudiosos atualmente.

A sustentabilidade constitui um dos maiores desafios da humanidade, sendo necessária uma mudança na abordagem do desenvolvimento. Um dos principais problemas a ser enfrentado é a geração e o acúmulo de resíduos sólidos que se encontram no estado sólido ou semi-sólido e resultam de atividades de origem industrial, doméstica, hospitalar, comercial, agrícola, de serviços e de varrição (ABNT, 2004). O acúmulo é creditado a décadas de descuido com a questão, sendo tratada apenas como uma consequência inevitável do desenvolvimento econômico, como é o caso dos pneus.

A grande quantidade de pneus inservíveis descartados, no Brasil e no mundo, fez com que este se constituísse em um problema de impacto ambiental, em função da sua composição e durabilidade, bem como do seu volume e compressibilidade. Entende-se como pneus inservíveis aqueles que não possuem mais nenhuma possibilidade de recauchutagem ou recapagem. Eles poluem o solo, a água, o ar, o mar e contribuem para uma séria questão de saúde pública atual, pois podem acumular 
água favorecendo a profileração do Aedes aegypti, mosquito transmissor de doenças como dengue, zika e chikungunya.

No Brasil, a Resolução CONAMA № 258/99 determinou que as empresas fabricantes e as importadoras de pneumáticos fossem obrigadas a coletar e dar destinação final ambientalmente adequada aos pneus inservíveis (BRASIL, 1999). Revogada, posteriormente, pela publicação da Resolução n 416/09 e adicionadas à instituição do Política Nacional de Resíduos Sólidos em 2010, tem-se buscado soluções para o gerenciamento dos pneus inservíveis.

Os pneus, ao final de sua vida útil, podem ser utilizados como combustível alternativo e, quando reciclados, podem ser transformados em tapetes para automóveis, solado de sapato, pisos industriais, pisos de quadras esportivas, borrachas de vedação. O pó gerado na recauchutagem e seus restos moídos podem ser usados na composição de asfalto de maior elasticidade e durabilidade.

A utilização dos pneus inservíveis como combustível alternativo em fornos de cimento, também chamado de coprocessamento, tem sido a alternativa de destinação mais buscada no Brasil e em outros países. O coprocessamento proporciona o aproveitamento térmico e a valorização energética deste resíduo, o que reduz o uso de combustíveis fósseis não-renováveis. Além disso, o aço contido nos pneus e as cinzas resultantes da queima podem ser incorporados ao cimento. Porém, alguns fatores legais e ambientais devem ser observados neste processo, como a geração de gases nocivos como monóxido de carbono (CO), óxidos de enxofre $\left(\mathrm{SO}_{\mathrm{x}}\right)$, óxidos de nitrogênio $\left(\mathrm{NO}_{\mathrm{x}}\right)$, além de dioxinas e furanos.

Há ainda a busca por métodos mais "verdes" de produção dos pneus, com o desenvolvimento de alternativas sustentáveis a fim de prolongar a sua vida útil, levando a uma menor geração de pneus inservíveis, por meio de adição de sílica e silano à composíção.

Com este trabalho, objetiva-se identificar as normas para licenciamento da utilização ou coprocessamento de resíduos industriais, especificamente o pneu inservível, e os padrões estabelecidos por lei para emissões de dioxinas e furanos no Brasil e no mundo. Busca-se também identificar, por meio de revisão da literatura, se, apesar de diminuir a geração de pneus inservíveis, o aumento da vida útil do pneu 
poderia causar impactos em outras fases do seu ciclo de vida, inclusive, na sua utilização como combustível alternativo.

\section{MÉTODO}

A metodologia utilizada neste trabalho foi a revisão da literatura e a busca de dados secundários, por meio de consulta a livros, artigos e outras fontes de caráter científico já publicadas.

\section{REVISÃO DE LITERATURA}

\subsection{Pneus}

O pneu é o produto da combinação de matérias-primas e processos e o elemento de contato entre o veículo e a via sobre a qual este trafega. A primeira iniciativa de definição de pneus por uma legislação foi estabelecida pela Resolução do Conselho Nacional de Meio Ambiente (CONAMA) n²58/99 que considerava:

- pneu ou pneumático: todo artefato inflável, constituído basicamente por borracha e materiais de reforço utilizados para rodagem em veículos automotores e bicicletas. Esta definição foi atribuída em nova redação pela Resolução n³01/02;

- pneu ou pneumático novo: aquele que nunca foi utilizado para rodagem sob qualquer forma;

- pneu ou pneumático reformado: todo pneumático que foi submetido a algum tipo de processo industrial com o fim específico de aumentar sua vida útil de rodagem em meios de transporte, tais como recapagem, recauchutagem ou remoldagem;

- pneu ou pneumático inservível: aquele que não mais se presta a processo de reforma que permita condição de rodagem adicional. 
Os principais polímeros utilizados no processo de fabrico dos pneus são a borracha natural, derivada da seiva das árvores Hevea brasiliensis, e a borracha sintética, derivada do petróleo. A elas são adicionados químicos como negro de fumo, sílica, enxofre, além de susbstâncias aceleradoras, plastificantes, antioxidantes e antiozonantes, para conferir suas propriedades específicas e bastante variáveis. Além da matéria-prima polimérica, os pneus são compostos por tecido de náilon e aço. A composição dos pneus varia com o fabricante, com sua aplicação e exigências de performance (ANIP, 2016).

O negro de fumo é um dos aditivos principais dos pneus, ao qual é atribuída a função de aumento da resistência do borracha. Trata-se de um pó de carvão muito fino, derivado da fuligem recolhida a partir de óleo queimado. Ele que confere a cor escura característica da borracha.

A adição de enxofre à borracha, processo conhecido como vulcanização, diminui sua viscosidade e aumenta a resistência. Isso ocorre porque os átomos de enxofre criam ligadas "cruzadas" entre as moléculas da borracha, impedindo-as de se movimentar. Essa adição também torna a borracha resistente à temperatura (SOARES, 2015). A vulcanização é um processo quase que irreversível e faz com que um pneu leve em média 600 anos para se degradar se disposto inadequadamente no meio ambiente.

Segundo dados da Associação Nacional da Indústria de Pneumáticos (ANIP), foram produzidos anualmente, em média, mais de 63 milhões de pneus nos últimos 11 anos no Brasil. Em 2016, somando todas as categorias (carga, passeio, moto, agrícola e outros), a produção foi de 67.870 .350 pneus (ANIP, 2016). Ao final de sua vida útil, esses milhares de pneus serão considerados inservíveis, podendo se transformar em um grande passivo ambiental.

O resíduo de pneus pode ser classificado, conforme NBR 10004/2004, como sendo não-perigoso Classe II A - não-inerte, por apresentar teores de metais (zinco e manganês) no extrato solubilizado superiores aos padrões estabelecidos por esta mesma norma (BERTOLLO et al., 2002).

Considerando que os pneus inservíveis dispostos inadequadamente constituem passivo ambiental, que resulta em sério risco ao meio ambiente e à saúde pública, com 
a Resolução CONAMA n-258/99, foi introduzido o princípio da responsabilidade do produtor e do importador pela coleta e destinação final ambientalmente adequada a esses pneus. Essa resolução estabeleceu, ainda, os prazos e quantidade a serem atendidos (BRASIL, 1999a).

A partir de $1^{\circ}$ de janeiro de 2002, para cada quatro pneus produzidos ou importados (novos ou reformados), as empresas fabricantes e as importadoras deveriam dar destinação final a um pneu inservível. A partir de $1^{\circ}$ janeiro de 2003, a relação passou a ser de dois pneus produzidos ou importados (novos ou reformados) para um pneu inservível com destinção final adequada. A partir de $1^{\circ}$ de janeiro de 2004, as empresas fabricantes e as importadoras deveriam dar destinação final a um pneu inservível para cada pneu produzido ou importado novo e, no caso de pneus reformados importados, para cada quatro, cinco pneus inservíveis deveriam ter destinação final por parte dos importadores. A partir do primeiro dia do ano de 2005, a relação cresceu para cada quatro pneus produzidos ou importados novos, cinco pneus usados deveriam ter destinação final e, para cada 3 pneus importados reformados de qualquer tipo, as importadoras deveriam dar destinação final a quatro pneumáticos inservíveis (BRASIL, 1999a). Depois da publicação da Resolução, 26 de agosto de 1999, ficou proibida a disposição de pneumáticos inservíveis em aterros sanitários, mar, rios, lagos ou riachos, terrenos baldios ou alagadiços, e a queima a céu aberto (BRASIL, 1999a).

A Resolução CONAMA № 416, de 30 de setembro de 2009, revoga as Resoluções n 258/1999 e no 301/2002, dispondo sobre a prevenção à degradação ambiental causada por pneus inservíveis e sua destinação ambientalmente adequada, além de dar outras providências. Ela traz outras definições para pneus, para destinação ambientalmente adequada, para pontos de coleta e para central de armazenamento. Ela estabelece que as empresas fabricantes ou importadoras deverão dar destinação adequada a um pneu inservível para cada pneu novo comercializado para o mercado de reposição, sendo a quantidade convertida em peso para efeito de controle e fiscalização, considerando o fator de desgaste de $30 \%$ (trinta por cento) sobre o peso do pneu novo produzido ou importado. Fica determinado por esta Resolução que os fabricantes e importadores de pneus novos devem declarar ao Instituto Brasileiro do 
Meio Ambiente e dos Recursos Naturais Renováveis - IBAMA, em uma periodicidade máxima de 01 (um) ano, por meio do Cadastro Técnico Federal - CTF, a destinação adequada dos pneus inservíveis. Esta determinação também é atribuída aos destinadores. (BRASIL, 2009)

A Instrução Normativa $\mathrm{n}^{0}$ 1, de 18 de março de 2010, que está relacionada à Resolução CONAMA N.ํ 416/2009, institui os procedimentos necessários ao seu cumprimento e apresenta algumas determinações considerando que a referida Resolução demanda ao IBAMA determinadas atividades fundamentais para a sua implementação (BRASIL, 2010a).

Na Europa, também é proibida a disposição em aterros de pneus inteiros a partir de 2003 e de pneus triturados a partir de 2006, resultado da Diretiva Europeia 1999/31/CE, de 26 de Abril de 1999. Assim, os Estados-Membros ficam obrigados a concentrarem os seus esforços na responsabilidade ambiental e em recolher e tratar adequadamente os seus pneus usados. Não existe nenhum regulamento europeu específico para recolher e tratar pneus usados. Cada Estado-Membro poderá escolher o seu próprio sistema de gestão dentre os três tipos existentes na Europa que são: o sistema de responsabilidade do produtor, o sistema de taxas e o sistema de mercado livre. Os países podem mudar de um sistema de gestão para outro (VALORPNEU, 2017).

No sistema de responsabilidade do produtor, os fabricantes ficam responsáveis por recolher e tratar adequadamente os pneus em final de vida e ao Estado cabe definir a estrutura reguladora que irá enquadrar a gestão destes resíduos. Em países que escolheram esta opção de sistema de gestão, os fabricantes criam um setor de atividade especializada nesta área, que é representado por uma ou mais entidades gestoras. No ato de compra de um pneus novo, é cobrado um valor de contarapartida que serve para financiar este sistema e que, dependendo do país, pode estar ou não visível na fatura.

No sistema de taxas, um imposto determinado pelo Estado é cobrado aos fabricantes de pneus e normalmente é repassado ao comprador. Este valor será usado para finaciar a coleta e o tratamento de pneus em final de vida. Assim, fica a cargo do Estado o processamento dos pneus e a remuneração dos operadores desse serviço. 
Para o sistema de mercado livre, o Estado define os objetivos de coleta e tratamento de pneus usados, mas não determina nenhum responsável direto por esta gestão. O detentor final dos pneus usados fica responsável por destiná-lo adequadamente. Assim, os operadores de coleta e tratamento competem uns com os outros e são livres para promover práticas de valorização a custo otimizado.

Segundo a Valorpneu (2017), entidade gestora em Portugal, o sistema de responsabilidade do produtor é o que apresenta meios e resultados mais eficientes para alcançar o objetivo de coleta e tratamento de $100 \%$ dos pneus usados.

A Figura 1 mostra a organização da gestão dos resíduos de pneus em fim de vida na Europa em 2015 e o ano em que o modelo de gerenciamento de responsabilidade foi definido nos respectivos países que o adotam.

A maior parte dos países europeus utilizam o sistema de responsabilidade do produtor. Esse grupo de países inclui Noruega, Turquia e 19 países da União Europeia, sendo eles: Suécia, Finlândia, Estônia, Letônia, Lituânia, Polônia, República Tcheca, Eslováquia, Hungria, Romênia, Bulgária, Grécia, Holanda, Bélgica, França, Itália, Eslovênia, Portugal e Espanha (ETRMA, 2015). Esse modelo é seguido de diversas maneiras, desde um sistema em que uma única empresa de gestão lida com a coleta e tratamento do pneu em final de vida útil em um país, como em Portugal, Holanda e Suécia, podendo haver também várias empresas de gestão, como ocorre na Itália, França e Espanha; ou ainda, por meio de responsabilidade individual do produtor, caso da Hungria (ETRMA, 2015).

O sistema de taxas é aplicado na Dinamarca e na Croácia, sendo financiado por um imposto cobrado sobre os produtores de pneumáticos e, posteriormente, repassado ao consumidor. Cada país é responsável pela gestão desses resíduos (ETRMA, 2015). Já o sistema de mercado livre é adotado na Áustria, Suíça, Alemanha, Reino Unido e em alguns países do sudeste da Europa (ETRMA, 2015).

Nos Estados Unidos, o sistema implementado é o de mercado livre, não existe uma legislação federal regulamentadora e cada estado possui sua própria legislação para pneus. Segundo Campos (2006), alguns estados têm fundos específicos para lidar com os resíduos de pneus usados, baseados em taxas cobradas, outros proíbem o comerciante de pneus de cobrar taxas adicionais para a destinação dos pneus usados. 
Em alguns estados, é proibida a deposição de pneus inteiros em aterros enquanto em outros, a de pneus triturados.

Figura 1: Organização da gestão dos resíduos de pneus em fim de vida na Europa em 2015

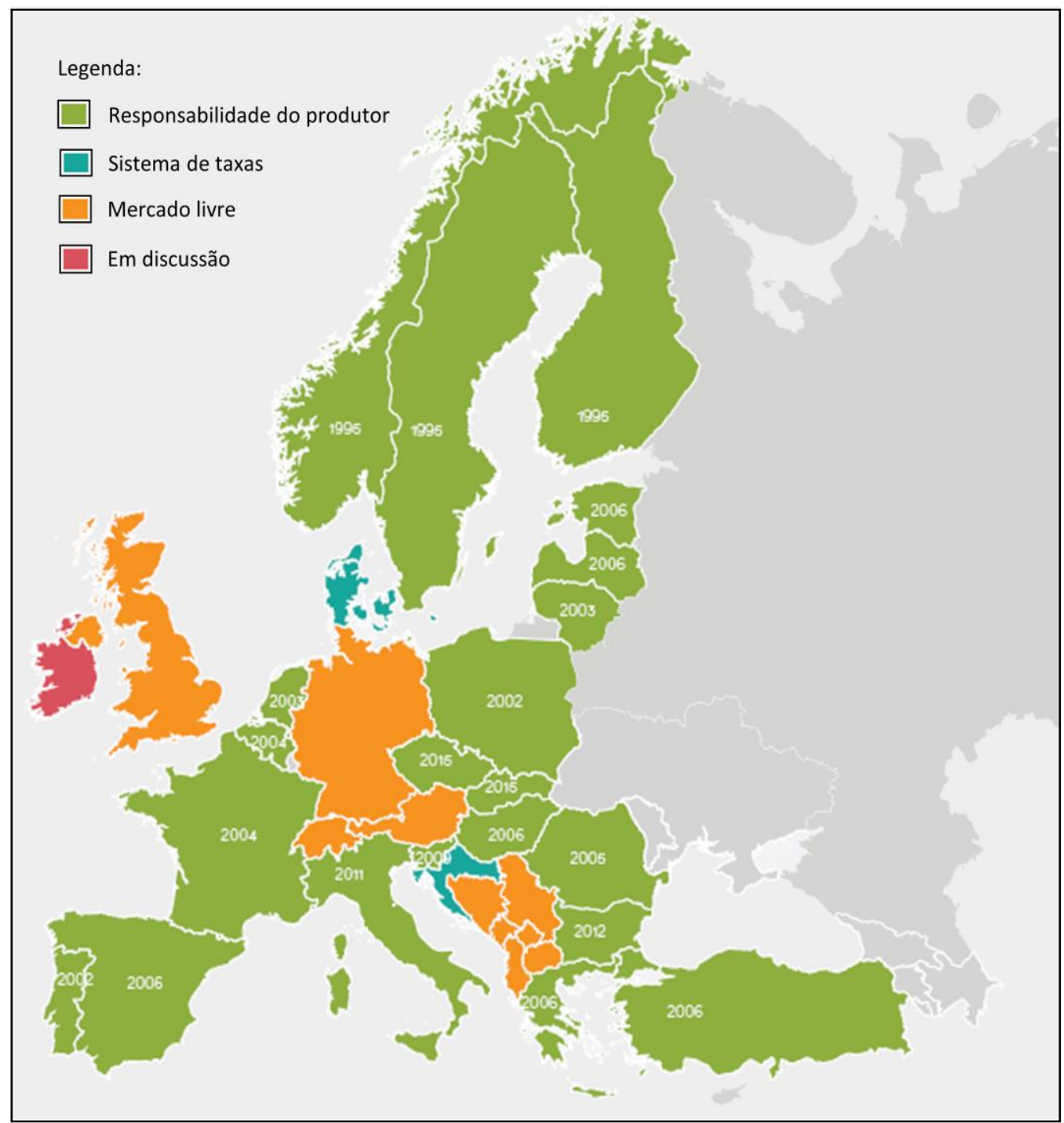

Fonte: Adaptado de ETRMA, 2015

\subsection{Principais destinações dos pneus inservíveis}

A Associação Nacional da Indústria de Pneumáticos - ANIP é uma entidade representa as empresas fabricantes de pneumáticos de todo o Brasil desde 1960. Nesse contexto, para atuar na coleta e destinação de pneus inservíveis, procedimento que redunda no atendimento da finalidade ambiental já expressa na revogada 
Resolução 258/99 do CONAMA, as indústrias de pneumáticos valem-se de instrumentos implantados pela ANIP, que criou o Programa Nacional de Coleta e Destinação de Pneus Inservíveis. Esse programa, que contava em 2014 com a participação de 834 pontos de coleta em todos os estados do país e no Distrito Federal, tornava necessária a constituição de uma entidade exclusivamente dedicada à gestão e aprimoramento dos trabalhos sobre o pós-consumo dos pneumáticos. Assim, foi criada em 2007 a Reciclanip, com base no modelo europeu, com a diferença que nos países da Europa o custo é compartilhado entre os diversos participantes da cadeia e, no Brasil, até o momento é pago apenas pelos fabricantes e importadores. Segundo a ANIP (2015), a Reciclanip, associção sem fins lucrativos, tem por missão assegurar a sustentabilidade do processo de coleta e destinação de pneus inservíveis de responsabilidade dos fabricantes de pneus em todas as regiões do país, atuando de forma responsável nas áreas ambiental, social e econômica.

O Programa funciona em âmbito nacional, a partir da celebração de convênios de cooperação mútua, com instalação dos pontos de coleta, locais cobertos disponibilizados e controlados pelas prefeituras municipais e outros parceiros, para onde são levados os pneus recolhidos pelo serviço público, ou descartados voluntariamente pelo munícipe e por empresas. A partir desses pontos de coleta, a Reciclanip recolhe os pneus considerados inservíveis e os encaminha para a destinação final ambientalmente adequada, realizada por empresas devidamente autorizadas e licenciadas pelos órgãos ambientais.

O desenvolvimento de um sistema de logística reversa de produtos e embalagens em final de vida útil, de forma independente do serviço público de limpeza urbana e de manejo dos resíduos sólidos, tornou-se obrigatório para fabricantes, distribuidores e importadores a partir da aprovação da Política Nacional de Resíduos Sólidos (PNRS), em 02 de agosto de 2010 (BRASIL, 2010b), o que torna o papel da Reciclanip com os pneus inservíveis mais relevante.

Segundo dados da ANIP (2015), a forma mais comum de destinação dos pneus inservíveis é como combustível alternativo para a indústria de cimento, que correspondeu a $69,7 \%$ do total em 2014. Em segundo lugar, está a fabricação de granulado e pó de borracha para utilização em artefatos de borracha, ou asfalto- 
borracha, respondendo por $17,8 \%$ da destinação. Na sequência, está a laminação, que utiliza o pneu inservível como matéria-prima para fabricar solado de sapato, dutos fluviais, que representam $6,0 \%$. O aço corresponde a 6,5\% e é também reaproveitado na fabricação do cimento ou pela indústria siderúrgica.

\subsubsection{Coprocessamento de pneu inservível e outros resíduos}

O uso do pneus como combustível alternativo, ou seja, seu coprocessamento, nos fornos de clínquer ${ }^{1}$ proporciona 0 aproveitamento térmico e a valorização energética deste resíduo, o que reduz o uso de combustíveis fósseis não-renováveis, além disso, o aço contido nos pneus e as cinzas resultantes da queima podem ser incorporados ao clínquer. Dentre outras vantagens da substituição dos combustíveis tradicionais, tais como coque de petróleo, por pneus inservíveis, estão a menor geração de $\mathrm{SO}_{2}$ e NOx, redução do custo de produção do cimento, menor formação de dioxinas e furanos devido ao elevado tempo de residência em um ambiente alcalino e com presença de sulfatos, característicos do processo de produção do cimento (LAGARINHOS, 2011).

As disposições, procedimentos, critérios básicos e aspectos técnicos específicos de licenciamento ambiental para as atividades de coprocessamento de resíduos em fornos rotativos de clínquer, para a fabricação de cimento estão contidos na Resolução CONAMA no 264/99. Nela estão estabelecidos os limites máximos de emissão atmosférica de alguns poluentes para essas atividades, dentre eles: hidrocarbonetos totais, monóxido de carbono e metais pesados, como chumbo, mercúrio e cádmio. Os limites de emissão dos poluentes poderão ser mais restritivos, a critério do Órgão Ambiental local, em função de particularidades regionais. (BRASIL, 1999b).

A Resolução $n^{\circ} 264$ do CONAMA também estabelece quais parâmetros de processo e emissões atmosféricas devem ser monitoradas continuamente e que os relatórios de monitoramento devem ser encaminhados ao Órgão Ambiental competente de acordo com a freqüência solicitada (BRASIL, 1999b).

\footnotetext{
${ }^{1} \mathrm{O}$ clínquer, constituinte básico do cimento, resulta da queima de rochas calcárias e argilosas em um forno rotativo a $1450^{\circ} \mathrm{C}$. A ele, é adicionado de 3 a 6\% de gesso a fim de controlar a cinética de hidratação do cimento (MARQUES, 2000).
} 
A Resolução CONAMA № 316/02 dispõe sobre procedimentos e critérios para o licenciamento e para o funcionamento de sistemas de tratamento térmico de resíduos, levando em consideração que o princípio da precaução é fundamental para o desenvolvimento sustentável e que os sistemas de tratamento térmico de resíduos são fontes potenciais de risco ambiental e de emissão de poluentes perigosos. Ela define os limites de emissão para vários poluentes, inclusive dioxinas e furanos $\left(0,5 \mathrm{ng} / \mathrm{Nm}^{3}\right.$ expressos em TEQ - total de toxicidade equivalente da 2,3,7,8 TCDD (tetraclorodibenzo-para-dioxina)) em complemento à Resolução no 264/99 do CONAMA que não apresenta esses valores para o co-processamento de resíduos em fornos rotativos de produção de clínquer (BRASIL, 2002).

Nos Estados Unidos, sob a autoridade do Clean Air Act, a Agência de Proteção Ambiental Americana (Environmental Protection Agency - EPA) promulgou, em maio de 1999, padrões nacionais de emissão para fornos de cimenteiras novos e já existentes. As regulações específicas para dioxinas e furanos foi de limite de $0,2 \mathrm{ng} \quad \mathrm{I}-\mathrm{TEQ} / \mathrm{m}^{3}$ (KARSTENSEN, 2007).

Segundo a Associação Brasileira de Cimento Portland (ABCP), uma grande variedade de resíduos substitutos de combustível são utilizados na fabricação de cimento, a saber: solventes; resíduos oleosos e resíduos têxteis; óleos usados (de carro e fábricas); pneus usados e resíduos de picagem de veículos; graxas, lamas de processos químicos e de destilação; resíduos de empacotamento e de borracha; resíduos plásticos, de serragem e de papel; lama de esgoto, ossos de animais e grão vencidos; lama com alumina (alumínio); lamas siderúrgicas (ferro); areia de fundição (sílica); resíduos da fabricação de vidros (flúor); gesso, cinzas e escórias (ABCP, 2016).

Na União Europeia, a Diretiva 2000/76/CE de 4 de Dezembro de 2000, relativa à incineração de resíduos, tem por objetivo prevenir ou, na medida do possível, reduzir ao mínimo os efeitos negativos no ambiente, em especial a poluição resultante das emissões para a atmosfera, o solo e as águas superficiais e subterrâneas, bem como os riscos para a saúde humana resultantes da incineração e coincineração de resíduos. Ela determina os valores-limite de emissões totais de poluentes para fornos de cimento de coincineração de resíduos, conforme mostra o Quadro 1. Os valores-limite de 
emissão para o monóxido de carbono podem ser fixados pela autoridade competente (EUROPEAN UNION, 2000).

Quadro 1: Valores-limite de emissões para fornos de cimento de coincineração de resíduos

\begin{tabular}{|c|c|}
\hline Poluente & $C^{a}$ \\
\hline Poeiras totais & 30 \\
\hline $\mathrm{HCl}$ & 10 \\
\hline $\mathrm{HF}$ & 1 \\
\hline $\mathrm{NO}_{\mathrm{x}}$ & $500^{b} / 800^{c}$ \\
\hline $\mathrm{Cd}+\mathrm{Tl}$ & 0,05 \\
\hline $\mathrm{Hg}$ & 0,05 \\
\hline $\mathrm{Sb}, \mathrm{As}, \mathrm{Pb}, \mathrm{Cr}, \mathrm{Co}, \mathrm{Cu}, \mathrm{Mn}, \mathrm{Ni}, \mathrm{V}$ & 0,5 \\
\hline Dioxinas e furanos & 0,1 \\
\hline $\mathrm{SO}_{2}$ & $50^{d}$ \\
\hline COT & $10^{d}$ \\
\hline \multicolumn{2}{|c|}{$\begin{array}{l}\text { a- Todos os valores expressos em } \mathrm{mg} / \mathrm{m} 3 \text {, exceto dioxinas e furanos expressos em } \mathrm{ng} / \mathrm{m} 3 \\
\text { b- Para novas instalações } \\
\text { c- Para instalações já existentes } \\
\text { d- A autoridade competente pode autorizar isenções nos casos em que o COT e o } \mathrm{SO}_{2} \text { não } \\
\text { resultem da incineração de resíduos. }\end{array}$} \\
\hline
\end{tabular}

Fonte: Diretiva 2000/76/CE, União Europeia

Ainda segundo a ABCP (2016), em 2015, das 57 plantas integradas que possuem fornos rotativos para a produção de clínquer, 38 são plantas integradas com fornos rotativos licenciados para o coprocessamento de resíduos, representando $67 \%$ do parque industrial brasileiro. Dentre os substitutos de combustíveis, destacam-se os pneus inservíveis e o blend de resíduos ambos apresentando $41 \%$ do total em toneladas, conforme Figura 2. Já o coprocessamento de pneus inservíveis em fornos de cimento vem crescendo por ser considerado uma forma de destruição de toneladas de passivo ambiental. A evolução do coprocessamento é mostrado na Figura 3. 
Figura 2: Combustíveis fósseis alternativos utilizados na fabricação de cimento

Combustíveis fósseis alternativos

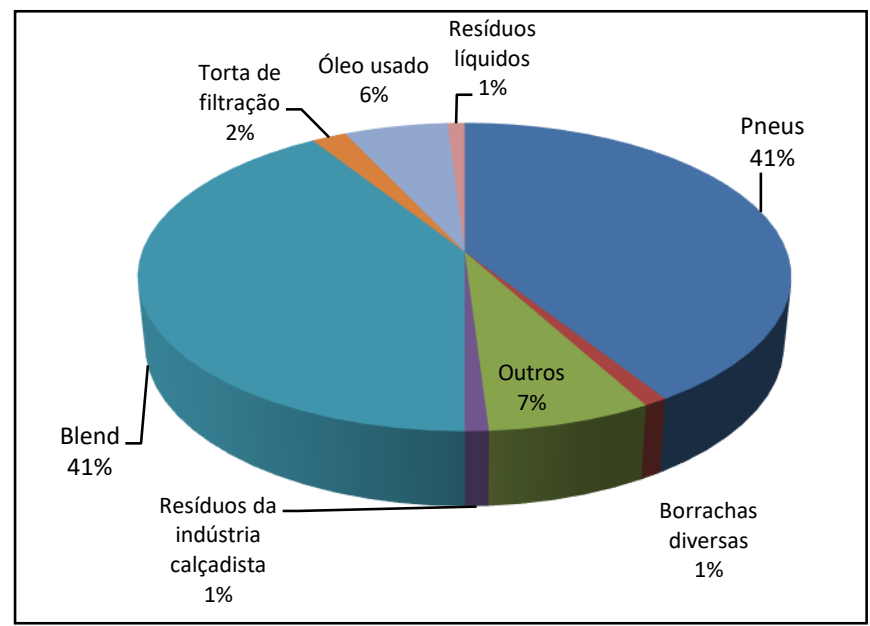

Fonte: Associação Brasileira de Cimento Portland, 2016

Figura 3: Evolução do coprocessamento de pneus no Brasil de 2005 a 2015

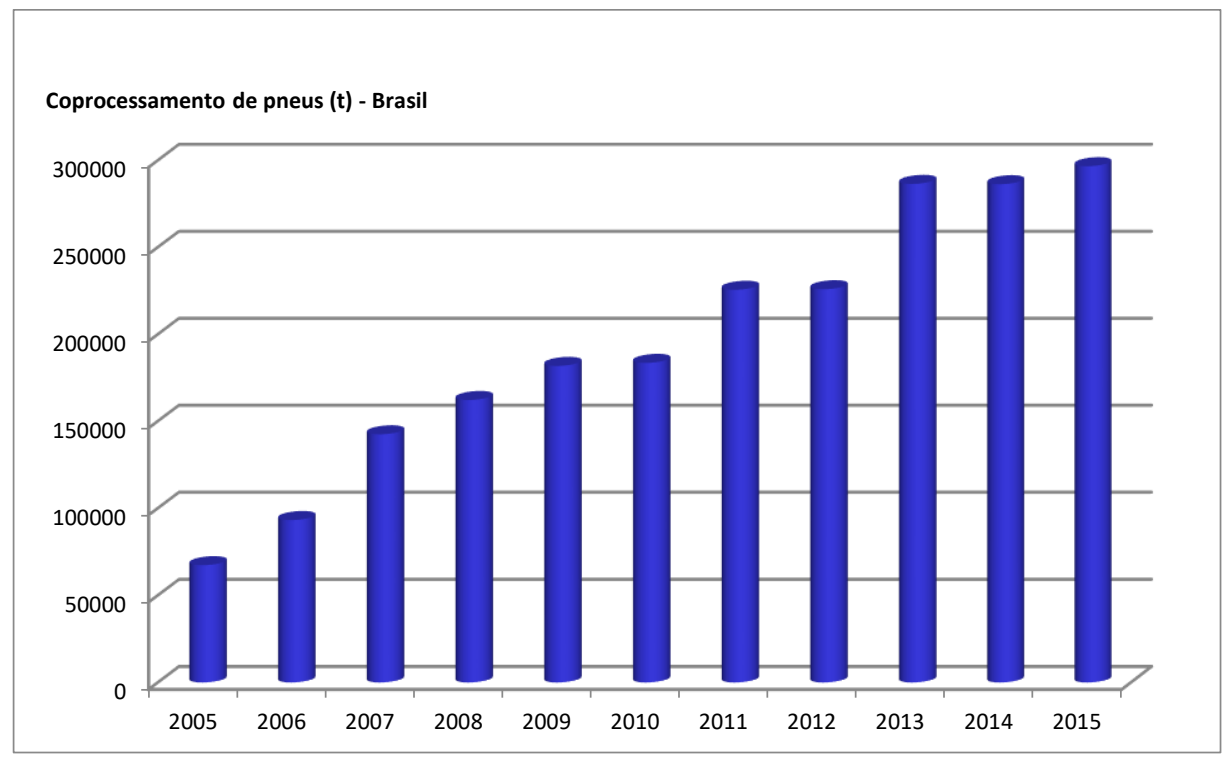

Fonte: Associação Brasileira de Cimento Portland, 2016

Segundo dados de 2015 da Associação Europeia de Cimentos (CEMBUREAU), em termos de recuperação de energia, 39\% dos combustíveis primários do forno de cimento (principalmente coque de petróleo e óleo) na União Europeia são substituídos por combustíveis alternativos. Desses combustíveis, 5,4\% são originários da biomassa de resíduos (como farinha de animais, resíduo de madeira, lodo de esgoto e serragem) e 33,4\% de outros resíduos (por exemplo, resíduos de pneus, óleo usado, solventes). 
Em 2050, 60\% da energia do forno poderia ser fornecida por combustíveis alternativos, levando a uma redução de $27 \%$ nas emissões de CO2 do combustível e economizando 7,7 milhões de toneladas (Mt) anualmente de carvão e coque de petróleo e 6 milhões de toneladas anualmente de matérias-primas. A CEMBUREAU também oferece suporte sobre como desenvolver o uso de combustíveis alternativos e biomassa de resíduos (CEMBUREAU, 2015).

Nos Estados Unidos em 2015, foram fabricados 279,7 milhões de pneus novos. Segundo dados da Associação de Fabricantes de Pneus dos Estados Unidos (U.S. Tire Manufacturer Association), neste mesmo ano, 117,31 milhões de pneus inservíveis foram reaproveitados energeticamente, o que corresponde a $48 \%$ do total gerado, sendo 45,97 milhões $(753,37$ mil toneladas) destinados ao coprocessamento em fornos de clínquer (USTIRES, 2017).

\subsection{Pneu "verde"}

Os pneus são produtos e composições de alta tecnologia. É um desafio para os desenvolvedores de pneus dominar o que eles chamam de "triângulo mágico" formado pelos objetivos conflitantes de aderência molhada, resistância à abrasão e resistência ao rolamento.

No passado, os pneus estavam equipados com negros de fumo e borracha de ESBR (butadieno-estireno polimerizado por emulsão), assim a melhora em um dos vértices do triângulo resultava em uma deterioração da propriedade correspondente de outro vértice (EVONIK, 2017).

Recentemente, tem-se introduzido a sílica para substituir o negro de fumo na mistura para a fabricação de pneus. Com a introdução das marcas de borracha S-SBR (butadieno-estireno polimerizado por solução) e da tecnologia Sílica/ Silano, tornou-se possível melhorar a resistência ao rolamento e a aderência molhada ao mesmo tempo e, dessa forma, desenvolver pneus de baixa resistência ao rolamento, também conhecidos como "pneus verdes", sem concessões em Segurança. A Figura 4 mostra a comparação entre os dois "triângulos mágicos". Os pneus verdes oferecem uma durabilidade comparável à classe de borracha E-SBR com base em negro de fumo, têm 
uma aderência significativamente melhor - especialmente em condições úmidas - e reduzem o consumo de combustível (EVONIK, 2017). Além da economia no consumo de combustível, há uma menor emissão de poluentes pelos veículos, e ainda menor geração de resíduos ao longo do tempo, visto que a durabilidade dos pneus aumenta.

Segundo a EVONIK, a sílica atua como um enchimento ativo e o silano é adicionado para unir quimicamente a borracha S-SBR e a sílica. No entanto, segundo Campos (2006), esta substituição pode ter consequências negativas no potencial de valorização energética do resíduo, pois diminui o valor energético da borracha e aumenta 0 teor de cinzas gerado durante 0 coprocessamento. Durante 0 coprocessamento de resíduos em fornos de cimento, parte das cinzas geradas é incorporada à massa. No entanto, não é claro o percentual máximo admitido na mistura, e as cinzas adicionais podem se tornar um outro passivo ambiental.

Figura 4: Comparação entre pneus pneus padrão e pneus com adição de Sílica/Silano

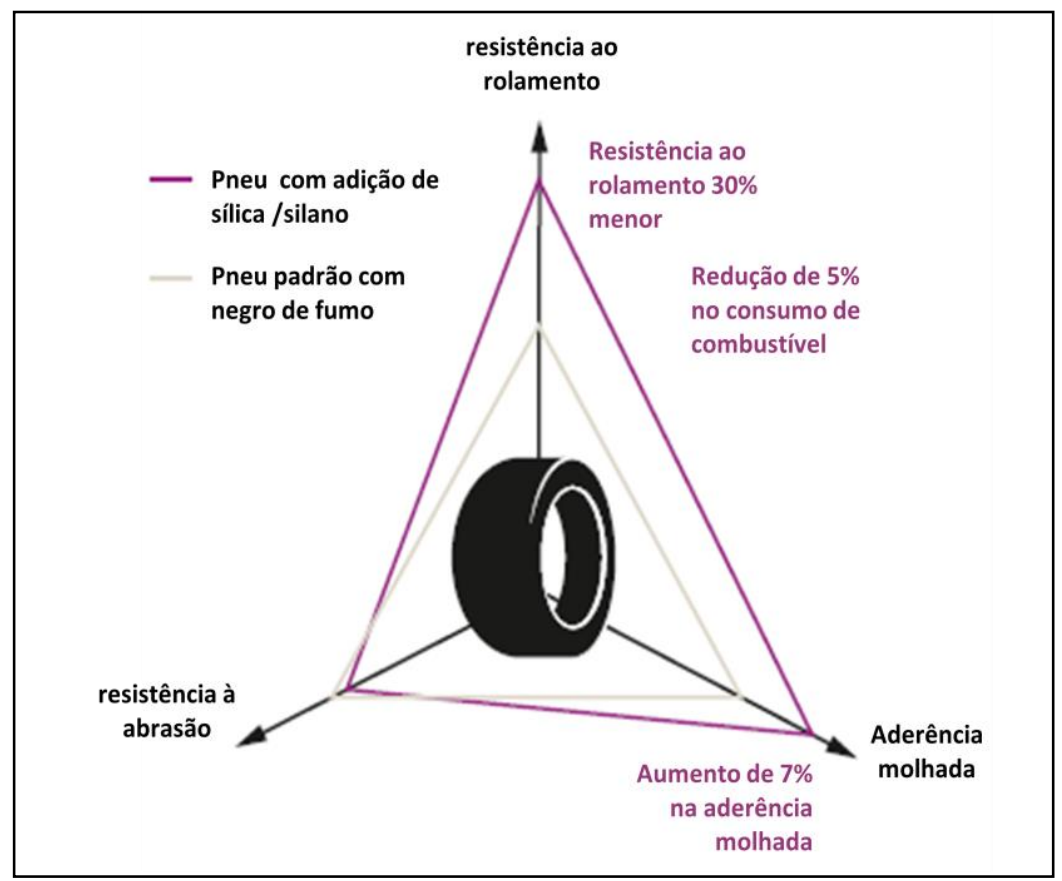

Fonte: Adaptado de Tyre go green - A life cycle assessment (EVONIK, 2017) 


\section{DISCUSSÃO DOS RESULTADOS}

Lagarinhos (2011), em estudo acerca da logística reversa dos pneus usados no Brasil, observou que a mesma já era exigida pela Resolução CONAMA n 416/2009, com a possibilidade da realização de acordos setoriais para facilitar sua implementação. Porém, não está prevista a retirada dos pneus inservíveis, que já constituíam um passivo ambiental, de aterros, lixões, rios, entre outros.

Para o autor, a logística reversa é um elo de fundamental importância no gerenciamento de pneus inservíveis, bem como seu dimensionamento para os fabricantes e importadores, devido ao custo da coleta, transporte e destinação destes resíduos para o cumprimento das metas estabelecidas (LAGARINHOS, 2011).

O estudo aponta que os fabricantes e importadores de pneus não realizam um trabalho em conjunto para desenvolver um modelo de logística reversa que reduza os custos; aumente a quantidade de pneus ainda servíveis para as empresas de reforma, por meio da seleção e triagem nos pontos de coleta; e aumente a quantidade de inservíveis para atender às empresas de beneficiamento e às de coprocessamento.

Souza (2011) também aponta que no Brasil a triagem e a classificação dos pneus usados são realizadas de forma dispersa, nos próprios geradores de pneu inservível. Em outros países, o procedimento, geralmente, se realiza de forma centralizada, classificando e encaminhando os pneus para os destinos adequados. A triagem e classificação descentralizadas, por não garantirem um padrão nacional, podem ocasionar o encaminhamento de pneus ainda em condição de uso e/ou remanufatura para reciclagem, reduzindo assim sua vida útil.

As dificuldades da logística como um todo do pneu ainda são apontadas pela ANIP. A Associação destaca a importância do transporte para o ciclo. O pneu, por ser um produto volumoso e pesado, cujo transporte é concentrado no modal rodoviário, seu custo em todo o ciclo é significativo para a indústria, desde a matéria-prima ao inservível descartado, agravado pelos custos relacionados à logística brasileira, como impostos sobre o frete, taxas de pedágio, alto índice de roubo de carga e qualidade das estradas brasileiras, que tornam o produto ainda menos competitivo. Como melhoria no 
ambiente institucional, a ANIP propões a desoneração do processo de logística reversa dos pneus inservíveis e redistribuição do custo (ANIP, 2015).

Além de todas as dificuldades da logística reversa dos penus inservíveis, foi contatado que no Brasil havia 834 pontos de coleta em 2014, número baixo comparado aos 5.570 municípios. Segundo o IBAMA (2016), dos municípios com mais de 100 mil habitantes, onde deveria ser implantado pelo menos um ponto de coleta conforme a Resolução CONAMA 416/09, em 11 não há pontos de coleta.

A ANIP (2015) relata que nem todos os importadores cumprem a obrigação legal de recolher os pneus inservíveis de sua responsabilidade, de acordo com as metas anuais estabelecidas pelo IBAMA. A partir do Relatório de Pneumáticos publicado anualmente pelo IBAMA, em que são consolidadas as insformações fornecidas pelos fabricantes e importadores sobre os volumes de pneus inservíveis destinados, a ANIP constatou que, no acumulado de 2009 a 2013, foi gerado um passivo de cerca de 150 mil toneladas de pneus inservíveis de responsabilidade dos importadores que não cumpriram sua obrigação legal. Assim, como melhoria no ambiente microeconômico, a ANIP propôs o equacionamento do passivo gerado pelo não cumprimento das metas de destinação de pneus inservíveis por tradings e distribuidores independentes de pneus importados. Ela propôs que, para os importadores que não cumprem suas metas de recolhimento e destinação, seja criada uma taxa ambiental paga previamente à importação e que os custos da logística reversa seja compartilhado entre distribuidores, revendedores, destinadores, consumidores finais de pneus, poder público, fabricantes e importadores.

O coprocessamento em fornos de cimenteiras é a destinação mais comum de destinação dos pneus inservíveis, correpondendo a $69,7 \%$ do total gerado segundo a ANIP (2015). Porém, na pirâmide de priorização do gerenciamento de resíduos sólidos, representada na Figura 5, esta é a umas das opções "menos nobres". É preciso desenvolver, paralelamente, formas de prevenção a fim de evitar a geração de resíduos e de minimização da demanda por matérias-primas, opções mais favováveis. 
Figura 5: Pirâmide de priorização do gerenciamento de resíduos sólidos

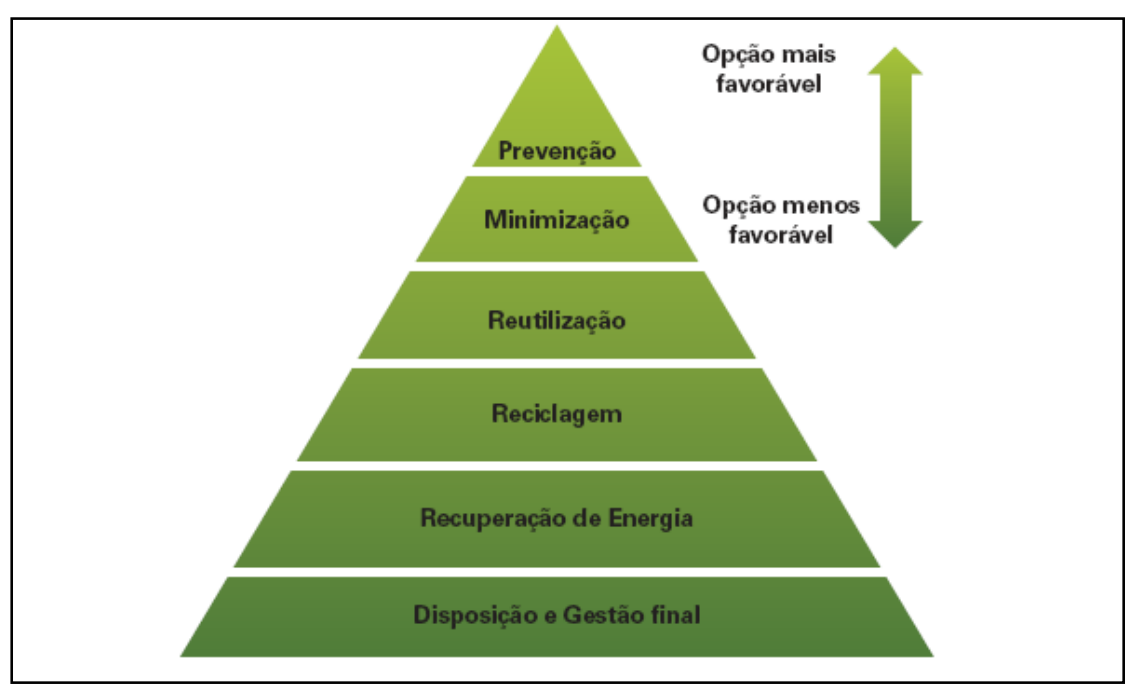

Fonte: Guia Técnico Ambiental da Indústria Cerâmica (FIEMG, 2013)

Os fabricantes e importadores, responsáveis pela adequada destinação dos pneus inservíveis gerados, necessitam apresentar um certificado de destinação que comprove tal destinação ao IBAMA anualmente, conforme a legislação. Em virtude disso, geralmente as empresas que possuem potencial para reaproveitar esse resíduo em seu ciclo produtivo recebem um valor monetário por tonelada para destinar corretamente os pneus inservíveis, fornecendo em troca disso o certificado de destinação de pneus inservíveis. Souza (2011), no decorrer de seu estudo, verificou em pesquisa de campo, a existência de um mercado de venda de certificados, em que as empresas que processam o pneu inservível e/ou o utilizam como substituto em seu ciclo produtivo obtém o certificado de destinação correta do pneu inservível e o comercializa com as empresas que deste necessitam. Souza (2011) aponta essa constatação como uma distorção, em que o gerador necessita custear o transporte do pneu inservível até o ponto de coleta, sem receber nenhuma remuneração para isso, enquanto o usuário do resíduo além de reduzir seu consumo de matéria prima ainda é remunerado por tal utilização.

Os valores de emissões atmosféricas gerados nas indústrias de cimento dependem das matérias-primas e combustíveis utilizados no processo, da temperatura e os níveis de oxigênio aplicados. Alguns autores, a exemplo de Lagarinhos (2011), indicam que o coprocessamento de pneus inservíveis em substituição a combustíveis 
tradicionais, tais como o coque do petróleo, nos fornos dessas indústrias, geram menores emissões de $\mathrm{SO}_{2}$ e $\mathrm{NO}_{x}$ e de dioxinas e furanos.

Porém, para Milanez (2007), há fragilidades institucionais das agências ambientais e limitada capacidade técnica nos países periféricos para que o coprocessamento de resíduos industriais em fornos de cimento no Brasil seja considerado como uma atividade adequada. O autor alguns problemas de saúde ocupacional e ambiental que justificam sua consideração. Ele defende um fortalecimento dos mecanismos de fiscalização e dos canais de participação social, para que Estado, empresários e sociedade possam reavaliar e rediscutir os riscos e as incertezas este tipo de destinação para os resíduos industriais.

Outro aspecto, pontuado por Santi e Sevá (2004), que deve ser levado em consideração nas discussões e, principalmente, nas decisões sobre a escolha dos combustíveis e sobre os riscos aceitáveis no processo de fabricação de cimento com emprego de resíduos é o Princípio da Precaução. Segundo eles, os entes públicos apresentam uma postura atrasada em relação aos riscos e sua disseminação para a saúde humana e para o meio ambiente em larga escala.

No entanto, como ressaltado por Rocha e Lemme (2013), é necessário ter cautela ao se utilizar do Princípio da Precaução para não invalidar a aplicação de novas tecnologias de produção ou mesmo tecnologias não usuais.

\section{CONSIDERAÇÕES FINAIS}

No Brasil, com a proibição da destinação final inadequada de pneus inservíveis, tais como a disposição em aterros sanitários, mar, rios, lagos ou riachos, terrenos baldios ou alagadiços, e queima a céu aberto em 1999, e com a obrigatoriedade da coleta e destinação destes pneus inservíveis, pelos fabricantes e importadores em 2002, a tecnologia mais utilizada para a destinação tem sido o coprocessamento em fornos de clínquer.

O coprocessamento de resíduos vem sendo cada vez mais utilizado, por motivações ambientais e energéticas. A substituição de combustíveis tradicionais, tais 
como o coque de petróleo, por resíduos como os de pneu inservível em fornos de clínquer reduz o custo do processo, visto que estes últimos apresentam preço inferior ao dos primeiros. Ambientalmente, o coprocessamento de pneus inservíveis é uma alternativa de eliminação de resíduos de grandes volume e peso que poderiam ter destinação de maior impacto ambiental, como a disposição em aterros.

A utilização destes resíduos como combustíveis alternativos em fornos de clínquer é regulamentada pela Resolução CONAMA n²64/99. Porém, percebe-se ainda fragilidades legais na sua regulação, na concessão de licenças e falhas na fiscalização devido a limitações institucionais das agências ambientais.

Foi observado na literatura que também ainda há muito a melhorar na fase de logística reversa dos pneus inservíveis, antes de eles chegarem aos fornos de cimento. A logística reversa deste resíduo no Brasil, responsabilidade dos fabricantes e importadores, é dispersa e a triagem e classificação ainda é falha.

As experiências internacionais no coprocessamento de resíduos se mostraram mais amadurecidas. Inclusive, com limites de emissão atmosférica mais restritivos que os praticados no Brasil.

\section{REFERÊNCIAS}

ASSOCIAÇÃO BRASILEIRA DE CIMENTO PORTLAND - ABCP. Panorama do coprocessamento - Brasil 2016. Disponível em: <http://coprocessamento.org.br/cms/wpcontent/uploads/2017/01/Panorama-coprocessamento_2016-1.pdf>. Acesso em: 24 jun. 2017.

ASSOCIAÇÃO BRASILEIRA DE NORMAS TÉCNICAS - ABNT. NBR 10004: Classificação de Resíduos Sólidos. Rio de Janeiro, ABNT, 2004, 71p.

ASSOCIAÇÃO NACIONAL DA INDÚSTRIA DE PNEUMÁTICOS - ANIP. Livro branco da indústria de pneus - uma política industrial para o setor. São Paulo, 2015. Disponível em: < http://www.anip.com.br/arquivos/f8201-white-book-versao-final.pdf>. Acesso em: 24 jun. 2017.

ASSOCIAÇÃO NACIONAL DA INDÚSTRIA DE PNEUMÁTICOS - ANIP. Produção e vendas 2016. Disponível em: <http://www.anip.com.br/index.php?cont=conteudo>. Acesso em 24 jun. 2017. 
BERTOLLO, S. M.; JÚNIOR, J. L. F.; SCHALCH, V. Benefícios da incorporação de borracha de pneus em pavimentos asfálticos. In: XVIII Congresso Interamericano de Ingenieria Sanitaria y Ambiental. 2002.

BRASIL. Ministério do Meio Ambiente, Conselho Nacional de Meio Ambiente, CONAMA, Resolução no 258, de 26 de agosto de 1999. Determina que as empresas fabricantes e as importadoras de pneumáticos ficam obrigadas a coletar e dar destinação final ambientalmente adequada aos pneus inservíveis. Publicada no DOU no 230, de 2 de dezembro de 1999. Brasília, 1999a.

Ministério do Meio Ambiente, Conselho Nacional de Meio Ambiente, CONAMA Resolução no 264, de 26 de agosto de 1999. Dispõe sobre Licenciamento de fornos rotativos de produção de clínquer para atividades de co-processamento de resíduos. Publicada no DOU no 54, de 20 de março de 2000. Brasília, 1999b.

- Ministério do Meio Ambiente, Conselho Nacional de Meio Ambiente, CONAMA Resolução no 316, de 29 de outubro de 2002. Dispõe sobre procedimentos e critérios para o funcionamento de sistemas de tratamento térmico de resíduos. Publicada no DOU no 224, de 20 de novembro de 2002. Brasília, 2002.

- Ministério do Meio Ambiente, Conselho Nacional de Meio Ambiente, CONAMA, Resolução $n^{\circ}$ 416, de 30 de setembro de 2009. Dispõe sobre a prevenção à degradação ambiental causada por pneus inservíveis e sua destinação ambientalmente adequada, e dá outras providências. Publicada no Diário Oficial da União em 01 de outubro de 2009. Brasília, 2009.

. Instrução Normativa no 1, de 18 de março de 2010. Brasília, 2010a. Disponível em : $<$ https://servicos.ibama.gov.br/ctf/manual/html/IN_01_2010_DOU.pdf>. Acesso em: 23 jun. 2017.

Política Nacional de Resíduos Sólidos. Lei Federal n 12.305, de 2 de agosto de 2010. Institui a Política Nacional de Resíduos Sólidos; altera a Lei no 9.605, de 12 de fevereiro de 1998; e dá outras providências. Brasília, 2010b.

CAMPOS, P. S. Aproveitamento industrial da borracha de pneu reciclada (a reciclagem do resíduo 160103 da L.E.R). 2006. Dissertação (mestrado). Universidade do Minho, Braga, Portugal, 2006.

CEMBUREAU - The European Cement Association. Activity report 2015. Brussels, 2015. Disponível em: <https://cembureau.eu/news-views/publications/2015-activity-report/>. Acesso em: 13 jul 2017.

ETRMA - European Tyre and Rubber Manufacturers' Association. End-of-life Tyre Report 2015. Brussels, 2015. Disponível em: <http://www.etrma.org/uploads/Modules/Documentsmanager/elt-report-v9a---final.pdf>. Acesso em: 05 jul 2017.

EUROPEAN UNION. Directive 1999/31/EC of the European Parliament and of the Council on the landfill of waste. April 26, 1999. Disponível em: <http://eur-lex.europa.eu/legalcontent/EN/TXT/PDF/?uri=CELEX:31999L0031\&from=PT>. Acesso em: 13 jul. 2017.

EUROPEAN UNION. Directive 2000/76/EC of the European Parliament and of the Council on the incineration of waste. December 4, 2000. Disponível em: <http://eur- 
lex.europa.eu/legal-content/EN/TXT/PDF/?uri=CELEX:32000L0076\&from=PT>. Acesso em: 13 jul. 2017.

EVONIK. Tires Go Green - A Life Cycle Assessment. 2017. Disponível em: < http://ultrasil.evonik.com/sites/lists/RE/DocumentsSI/Tires-go-gree-a-life-cycle-assesmentEN.pdf>. Acesso em 24 jun. 2017.

FEDERAÇÃO DAS INDÚSTRIAS DO ESTADO DE MINAS GERAIS (FIEMG). Guia técnico ambiental da indústria de cerâmica vermelha. Belo Horizonte: FIEMG, 2013. Disponível <http://www.feam.br/images/stories/producao_sustentavel/GUIAS_TECNICOS_AMBIENT AIS/guia_ceramica.pdf>. Acesso em: 03 jul. 2017.

Instituto Brasileiro do Meio Ambiente e dos Recursos Naturais Renováveis - IBAMA. Relatório pneumáticos: Resolução Conama no 416/09: 2016 (ano-base 2015). 76p. Brasília, 2016.

KARSTENSEN, K. H. A Literature Review on Co-processing of Alternative Fuels and raw Materials and Hazardous Wastes in Cement Kilns. 2007. Disponível em: < http://www.aitec-

ambiente.org/Portals/2/docs/pubblici/Documenti/Raccolta\%20bibliografica/Coprocessing\% 20literature\%20review\%202007.pdf>. Acesso em 25 jul. 2017.

LAGARINHOS, C.; TENÓRIO, J.. Reutilização, reciclagem e valorização energética de pneus no Brasil. Revista Polímeros: Ciência e Tecnologia, v. 18, n. 2, p.106-118, 2008.

LAGARINHOS C. A. F. Reciclagem de pneus: análise do impacto da legislação ambiental através da logística reversa. 2011. 291p. Tese (Doutorado) - Escola Politécnica da Universidade de São Paulo. Departamento de Engenharia Metalúrgica e de Materiais. São Paulo, 2011.

MARQUES, M. Coprocessamento em fornos de cimento. Revista Gerenciamento Ambiental, n. 6, 1999.

MARQUES, L. M. L. Coprocessamento de resíduos industriais em fornos de clinquer Aspectos do desempenho ambiental associados aos metais pesados. 2000. 135f. Dissertação (mestrado) - Departamento de Engenharia Sanitária e Ambiental, Universidade Federal de Santa Catarina, Florianópolis, 2000.

MEADOWS, D. H.; MEADOWS, D. L.; RANDERS, J. Limites do crescimento: um relatório para o projeto Clube de Roma sobre o dilema da humanidade. In: Limites do crescimento: um relatório para o projeto Clube de Roma sobre o dilema da humanidade. Perspectiva, 1972.

MILANEZ, B. Co-incineração de resíduos industriais em fornos de cimento: problemas e desafios. IX Encontro Nacional sobre Gestão Empresarial e Meio Ambiente. Universidade Positivo, Curitiba, 2007.

ROCHA, M. S. R.; LEMME, R. F. F. Inventário do Ciclo de Vida do Pneu Inservível como Combustível em Fornos de Cimenteiras, sob a Ótica das Emissões de $\mathbf{C O}_{2} .2013$. 79p. Escola Politécnica - Universidade Federal do Rio de Janeiro, Rio de Janeiro, 2013. 
SANTI, A. M. M.; SEVÁ FILHO, A. Combustíveis e Riscos Ambientais na Fabricação de Cimento; Casos na Região do Calcário ao Norte de Belo Horizonte e Possíveis Generalizações. In: II Encontro Nacional de Pós-Graduação e Pesquisa em Ambiente e Sociedade - ANPPAS. Campinas, SP, Brasil, 2004.

SOARES, A. I. C. C. R. Caracterização Físico-Química de Anomalias em Pneus - Criação de um protocolo de testes forenses. 2015. 112f. Dissertação (mestrado) - Instituto Superior Técnico. Lisboa, Portugal, 2015.

SOUZA, C. D. R. Análise da Cadeia de Valor Aplicada a Cadeias Logísticas Reversas. Uma Contribuição ao Reaproveitamento de Pneus Inservíveis. 2011. 111p. Dissertacão (mestrado). Programa de Engenharia de Transporte - COPPE - Universidade Federal do Rio de Janeiro, Rio de Janeiro, 2011.

U.S. Tire Manufacturers Association - 2015 U.S. Scrap Tire Management Summary. Washington, DC. May 2017. Disponível em: < https://www.ustires.org/system/files/scraptire_summ_2015_05_2017_Final_USTMA.pdf>. Acesso em: 14 jul. 2017.

VALORPNEU - Sociedade de Gestão de Pneus. A Gestão de pneus usados na Europa. 2017. Disponível em:

http://www.valorpneu.pt/artigo.aspx?lang=pt\&id_object=336\&name=A-Gestao-de-PneusUsados-na-Europa>. Acesso em: 24 mai. 2017.

WCED, World Commission on Environment and Development. Our Common Future. Oxford, U.K.: Oxford University Press, 1987. 